\title{
IAMJ
}

INTERNATIONAL

AYURVEDIC

MEDICAL JOURNAL

\section{STUDY ON EFFECT OF AYURVEDIC TREATMENT TO STABILIZE CREATININE LEVEL AND CONTROL PROGRESSION OF CHRONIC KIDNEY DISEASE}

\author{
Puthur Donata ${ }^{1}$, Krishnan Prasad ${ }^{2}, \operatorname{Varghese} \mathbf{R}^{3}$, Sahadevan C D \\ ${ }^{1}$ Senior consultant, ${ }^{4}$ Special Consultant, Jubilee Ayurveda Mission Hospital \& Research Institute, Jubilee \\ Mission P.O., Thrissur, Kerala, India-680005. \\ ${ }^{2}$ Scientist, ${ }^{3}$ Research coordinator, Jubilee Centre for Medical Research, Jubilee Mission Medical College \& \\ Research Institute, Thrissur, Kerala, India, 680005
}

Email: research@jmmc.ac.in

\section{https://doi.org/10.46607/iamjp04042020}

(Published online: May 2020)

Open Access

(C) International Ayurvedic Medical Journal, India 2020

Article Received: 30/03/2020 - Peer Reviewed: 07/05/2020 - Accepted for Publication: 16/05/2020

Check for updates

\begin{abstract}
Objectives: To study the effectiveness of enema in stabilizing creatinine level and controlling progression of Chronic Kidney Disease (CKD). Methods: This clinical observation describes the effectiveness of Ayurvedic therapy in our experience. Ten patients with CKD were treated at Jubilee Ayurveda Mission Hospital \& Research Institute for two years between 2016 and 2018. The patients were diagnosed with CKD as per the symptoms explained in the Ayurvedic texts along with modern lab tests. The treatments were decided based on the severity of the symptoms, health of the patients and any existing pre-conditions. The treatment for early stage patients included oral administration of medicines. For patients with higher stages of CKD, treatment with oral medicines and enema were administered. Result and Conclusions: The treatment resulted in stable creatinine level in blood and inhibited the progression of disease in patients.
\end{abstract}

Keywords: Chronic Kidney Disease (CKD), Ayurvedic therapy, Creatinine, Enema (vasti), 


\section{INTRODUCTION}

Chronic kidney disease (CKD) is defined as abnormalities of kidney structure or function, present for more than 3 months with implications for health. ${ }^{1}$ CKD is a condition, which develops over a period of time and adversely affects kidney's ability to efficiently filter blood. This results in accumulation of waste and excess fluid in the blood causing health problems. In India CKD is prevalent, though there is only limited data available regarding its statistics. The burden of chronic kidney disease (CKD) in India has not assessed accurately. The approximate prevalence of CKD is 800 per million population (PMP), and the incidence of the end stage renal disease (ESRD) is 150 -200 pmp. ${ }^{2}$ In India nearly 3500 renal transplants are done annually. In the year of 2004, 1,783,000 patients worldwide were receiving treatment for ESRD of which $77 \%$ were on dialysis and $23 \%$ had renal transplant and this number is increasing at a rate of $7 \%$ every year. ${ }^{3} \mathrm{CKD}$ is quite common in the United States with about 37 million people or about $15 \%$ of the population estimated to have it. That is more than 1 in 7 people developing CKD in their lifetime in the U.S.CKD is seen to be affecting more women than men. ${ }^{4}$

Two major causes of CKD are diabetes and hypertension. Over $2 / 3^{\text {rd }}$ of CKD can be attributed to these two major causes. Other risk factors include cardiovascular diseases, obesity and familial causes. Early CKD may not present any detectable symptoms as our kidneys have higher capacity to keep us healthy. ${ }^{4}$ However, as the disease progresses some symptoms start appearing. Edema in legs, hands and sometimes in face occurs as kidneys fail to get rid of excess fluid. Advanced CKD has symptoms such as chest pain, dry skin, feeling tired, nausea, sleep problems, weight loss etc. Patients with very advanced CKD known as the end-stage renal disease (ESRD) will need dialysis or kidney transplant to survive. ${ }^{5}$

The best option to prevent CKD is to control the major risk factors - high blood pressure ${ }^{6}$ and high blood sugar levels. ${ }^{7}$ Testing for CKD in people with either or both risk factors can help in early detection. Western medicine suggests managing CKD to slow the pro- gression to advanced stage. This could be achieved through lifestyle changes, proper medications and avoiding kidney injuries. ${ }^{4}$

Ayurveda, the Indian system of medicine, describes kidney diseases and suggests treatments to manage them, including CKD. According to Ayurveda, CKD is a progressive chronic inflammatory and degenerative disease of "Mutravahastrotas" i.e. metabolic derangement of renal system due to the vitiation of Tridoshas- the three doshas - Vata, Pitha and Kapha. ${ }^{7}$ The major etiological factors- "Nidana"- are due to an increase in life style diseases and the complications of diabetes, hypertension, obesity, fast food culture, over eating, eating junk food, chemical drugs, over dose of analgesics and antipyretics, unscientific use of strong antibiotics and cortisones etc., which trigger the condition. All these are concluded in Ayurvedic term as "Virudhaharam", "Dushivisham", "Adhyashanam" etc. ${ }^{8}$

Ayurveda treatment offers personalized lifestyle, food habits and medications which have holistic effects. The significant specialty of this treatment is based on detoxification, purification and elimination of the cellular level morbidities and toxins; simultaneously concentrating on healing and rejuvenation of degenerated tissues by Panchakarma Therapy (Five purification method). In this therapy, depending on the condition, patients are administered oral medicines to improve their metabolic enzymes so that the accumulated adherent cellular toxins would be transformed to get separated from the corresponding tissues. These are then eliminated by apt purification modalities. ${ }^{8}$

At our medical centre we treated patients who showed up with symptoms of varying levels of CKD, with Ayurvedic medicines. Here we present the details of the diagnosis and treatment, and the encouraging results of the Ayurvedic interventions in these patients.

\section{Materials and Methods}

\section{Study Design: Observational}

The patients were treated at Jubilee Ayurveda Mission Hospital \& Research Institute between 2016 and 2018. There were a total of ten patients. Six patients were men and the remaining four were females. The age of 
the patients ranged from 12 to 76 . Two were below the age of 50 and eight were above the age of 50 . The patients were diagnosed with CKD as per the symptoms explained in the Ayurvedic texts along with modern lab tests. The treatments were decided based on the severity of the symptoms, health of the patients and any existing pre-conditions. The summary of treatment for each patient is given in Table- 1 .

Table 1: Details of the patients and treatment given

\begin{tabular}{|l|l|l|l|l|l|l|}
\hline No: & Age & Gender & Any pre-existing conditions & Beginning of treatment & OralTreatment & Vasti Treatment \\
\hline 1 & 76 & M & HTN,DM & $10-1-2017$ & Yes & No \\
\hline 2 & 72 & M & HTN & $8-8-2017$ & Yes & No \\
\hline 3 & 68 & M & DM & $14-2-2017$ & Yes & No \\
\hline 4 & 67 & M & HTN & $8-9-2017$ & Yes & No \\
\hline 5 & 65 & F & & $12-6-2018$ & Yes & No \\
\hline 6 & 59 & M & LVD,AP & $28-5-2018$ & Yes & Yes \\
\hline 7 & 55 & M & HTN,DM & $10-8-2016$ & Yes & Yes \\
\hline 8 & 52 & F & DM & $11-10-2016$ & Yes & Yes \\
\hline 9 & 43 & F & HTN & $14-2-2017$ & Yes & No \\
\hline 10 & 12 & F & & $10-5-2016$ & Yes & \\
\hline
\end{tabular}

HTN-Hypertension, DM-Diabetes Mellitus, LVD-Left Ventricular Dysfunction, AP-Angioplasty

The general actions of Ayurvedic medicines given to the patients, along with those of Vasti, are summarized in Tables -2 and -3 respectively.

Table 2: Actions of oral medicines in CKD

- Anti-inflammatory

- Diuretic

- Enhance urine formation

- Reduce acidosis

- Anti-inflammatory antiseptic

- Rejuvenation

- Enhances metabolic function and detoxification

- Better excretion of toxins from the colon

- Tones up the enteric nervous system through myenteric plexus and submucosal plexus

- Restore the Mineral balance

- Immunostimulant and antioxident

\section{RESULTS}

\section{Ayurvedic treatment reduced/stabilized creatinine}

level in all patients: All male patients responded well to the Ayurvedic treatment and showed improved creatinine levels. Patient 1 , the oldest in the list, had the lowest variation in creatinine levels ranging between $1.5 \mathrm{mg} / \mathrm{dl}$ and $1.9 \mathrm{mg} / \mathrm{dl}$. Patient 3 had creatinine level $7.8 \mathrm{mg} / \mathrm{dl}$ at the beginning of treatment. The level was lowered to $5 \mathrm{mg} / \mathrm{dl}$ after a few visits and is stabilized
Table 3: $V a s t i-$ medicines and action
Ingredients
1. Rock salt
2. Cumin seed
3. Celery
4. Piper longum
5. Dried ginger
6. Terminalia chebula
Actions of Vasti in CKD

- Enema is Anti-inflammatory antiseptic treatment, which also reduces endotoxin level and histological renal and pancreatic damage.

- It reduces bacterial translocation

- Multidimensional systemic effect

at $5.44 \mathrm{mg} / \mathrm{dl}$. A remarkable result was observed in patient 4 who had an initial creatinine level of 9.2 $\mathrm{mg} / \mathrm{dl}$ which was brought down to $3 \mathrm{mg} / \mathrm{dl}$ and now stabilized around $5.5 \mathrm{mg} / \mathrm{dl}$. Rest of the male patients showed almost normal creatinine level all through the treatment. Female patients also showed similar trend in creatinine levels after treatment. Notable changes were seen in patient 8 and 10 . Patient 8 , who had an initial creatinine level of $7.2 \mathrm{mg} / \mathrm{dl}$, was reduced to 6 
$\mathrm{mg} / \mathrm{dl}$ and is now stabilized at $6.6 \mathrm{mg} / \mathrm{dl}$. Patient 10 was seen to have creatinine level of $5.1 \mathrm{mg} / \mathrm{dl}$ which came down to $3.8 \mathrm{mg} / \mathrm{dl}$ and is now at $4.2 \mathrm{mg} / \mathrm{dl}$.

From these data, it seems that the higher the initial level of creatinine, the better the response of the patients as seen in patients $3,4,8$ and 10 .

\section{Special case}

Patient No: 9 is a female with chronic renal failure at the age of 18 years. She had also her left kidney removed 22 years ago. Combined treatment of oral and vasti treatment has resulted in better patient response without proceeding to hemodialysis.

\section{DISCUSSION}

CKD is a progressive damage happening to kidneys over a period of time. It starts as a very mild damage in stage 1 to kidney failure in stage 5 . Most of the times there are no symptoms and so many people don't recognize earlier stages of CKD. Signs of early stage might be protein in urine. As the CKD progresses to higher stages, swelling in hands and feet develops along with back pain. Even though there is no cure for CKD, the progress could be slowed by controlling signs and symptoms. Usually medications to control high blood pressure and cholesterol are prescribed. Patients are usually advised to take a lower protein diet to reduce nitrogenous wastes in the body. Other medications include those to relieve swellings and improve anaemic conditions. However, these are just control measures and usually CKD progresses to ESRD, where patients need dialysis and may be transplant in the final stage. ${ }^{9}$

Creatinine level in urine is considered as one of the markers of kidney function. ${ }^{10}$ After the treatment under Ayurvedic system, we found that all the patients responded well to the treatment. They were recovering well and were able to maintain creatinine levels. These patients were advised to continue the medications, which are to be taken internally. They have reported that they are continuing the medications and are able to perform day to day activities without further hospitalization. Among the ten patients, four were CKD patients for more than 3 years. The fact that these patients still haven't advanced to the next stages of CKD clearly indicates that our treatment alone has stemmed the progress of the disease.

The oral treatment given at our clinical center addressed a multitude of symptoms as can be seen in Table-2. From this table it is clear that the Ayurvedic treatment is multidimensional, targeting all the possible disorders associated with CKD. It is worthwhile to mention the role of enema, in CKD. It is known as Vasti in Ayurvedic parlance. It is one of the Panchakarma Therapies. Vasti, the medicated retention enema, is the main purification process in CKD. It is a complex classical herbal formulation. After emulsification of the specific selected medicines in a special order the medicine is administered to the colon. ${ }^{11} \mathrm{Co}$ lon is the center of enteric nervous system which has a number of neural circuits-neural apparatus. These include myoenteric plexus and submucosal plexus which are involved in immuno responses, endocrine, paracrine functions and bacterial enzymes which functioning as neurotransmitters. ${ }^{12}$

The procto-colonic administration of specific medicines has been shown to be effective, suggesting possible involvements on neural processes in the inflammatory mechanism in kidney and immune system. The brain- gut axis communicates to the vagal pathways of gut and kidney and it reaches the brain very quickly. Then the brain communicates through the autonomic nerves system, which enforces the cell to cell elimination of bio-toxins from the body through the large intestine flush. ${ }^{13}$ Usually the patients feel getting light bodied, more energetic and refreshed after Vasti treatment for 5 consecutive days in a month. The lab investigations show a decrease in serum creatinine and blood urea levels. ${ }^{14}$

As more and more evidence surfaces about the role of enteric nervous system, for the overall health of the body, Vasti can be considered as an effective treatment method to purify the body. After all, CKD is inefficiency of the kidneys to remove toxins, and Vasti helps in rerouting the toxins out through colon, thereby reducing the stress on kidneys.

In addition, in modern medicine, there are quite a few side effects, which cause severe discomforts to the CKD patients. These side effects include hypotension, 
muscle cramps, sleep problems, hyperkalemia, fluid overload and depression. In our patients we didn't observe any such complications or side effects arising out of our treatment. ${ }^{15}$

Another advantage of Ayurvedic treatment is that it is more economical compared to modern medicine. The evidence from a cross-sectional study in India ${ }^{16}$ says the annual average expense of modern medications for CKD as direct cost is INR 25,836 (around US \$386) and for medications plus hemodialysis is INR 2,13,144 (around US \$3181). From this crosssectional study it can be seen that there is substantial increase in the cost of treatment of CKD when patients need hemodialysis. The maximum cost of the Vasti treatment is around Rs.300/- per day. The total cost of medicines including the Vasti done in hospital may cost maximum Rs 3000 per month and around Rs.36, 000 annually (just over US \$500).

\section{CONCLUSION}

This study shows that Ayurveda could be considered as an effective treatment option against CKD. It is effective in stabilizing the disease conditions and making patients healthy enough to carry on with their daily activities. Ayurveda provides a multidimensional internal treatment without side effects. In special cases, Vasti can be employed to enhance the effect of treatment. Ayurveda is comparatively a less expensive treatment option for a disease like CKD, which is becoming quite common among general population.

\section{REFERENCES}

1. Levin AS, Bilous RW, Coresh J. Chapter 1: Definition and classification of CKD. Kidney Int Suppl. 2013; 3:19-62.

2. Saini S, Arora D. Chronic kidney disease and role of palliative care. Hos Pal Med Int Jnl. 2018;2(6):358-360

3. Agarwal SK, Srivastava RK. Chronic kidney disease in India: challenges and solutions. Nephron clinical practice. 2009;111(3):c197-203

4. https://www.kidney.org/atoz/content/about-chronickidney-disease

5. https://www.niddk.nih.gov/health-information/kidneydisease/chronic-kidney-disease-ckd/what-is-chronickidney-disease\#symptoms

6. Kidney Disease Outcomes Quality Initiative (K/DOQI). K/DOQI clinical practice guidelines on hypertension and antihypertensive agents in chronic kid- ney disease. Am J Kidney Dis. 2004;43 (5 Suppl 1):S1-S290.

7. Tuttle K R, Bakris GL, Bilous RW, et al. Diabetic kidney disease: a report from an ADA Consensus Conference. Diabetes Care. 2014; 37:2864-2883

8. Acharya Vagbhata. Ashtanga Hridayam. Chowkhamba Sanskrit Series, B, 1956, $13^{\text {th }}$ chapter: Shloka number 8 \& 9 .

9. https://www.kidneyfund.org/kidney-disease/chronickidney-disease-ckd/stages-of-chronic-kidney-disease/

10. Guyton, A. C.,Hall, J.E(1996).Micturition, Diuretics and Kidney Disease. In: Textbook of medical physiology.9th ed. Philadelphia, W.B Saunders company, pp:405.

11. Acharya Vaidya Jadavaji Trikamji. Charakasamhita. $3^{\text {rd }}$ Ed. Satyabhamabai Pandurang, Bombay, 1941. $26^{\text {th }}$ Chapter: Shloka number 45-47.

12. Gupta P.K. and Singh R.H. A Conceptual Study on Vasti Effect. Ancient Science of Life. Vol. No XX January 2001 Pages 54-59.

13. Nampoothiri MV, Mahātēvan E, Jayadeep S. Principles and Practice of Vasti. Sarada Mahadeva Iyer Ayurvedic Educational \& Charitable Trust; 2010. $17^{\text {th }}$ chapter: The Enteric Nervous System:The Brain in the Gut.

14. Zou C, Wu YC, Lin QZ. Effects of Chinese herbal enema therapy combined basic treatment on BUN, SCr, UA, and IS in chronic renal failure patients. Zhongguo Zhong xi yi jie he za zhi Zhongguo Zhongxiyi jiehe za$\mathrm{zhi}=$ Chinese journal of integrated traditional and Western medicine. 2012 Sep;32(9):1192-5.

15. Whittaker CF, Miklich MA, Patel RS, Fink JC. Medication safety principles and practice in CKD. Clinical Journal of the American Society of Nephrology. 2018 Nov 7;13(11):1738-46.

16. Ahlawat R, Tiwari P, D'Cruz S. Direct Cost for Treating Chronic Kidney Disease at an Outpatient Setting of a Tertiary Hospital: Evidence from a Cross-Sectional Study. Value Health Reg Issues. 2017; 12:36-40.

\section{Source of Support: Nil \\ Conflict of Interest: None Declared}

How to cite this URL: Puthur Donata et al: Study On Effect Of Ayurvedic Treatment To Stabilize Creatinine Level And Control Progression Of Chronic Kidney Disease. International Ayurvedic Medical Journal \{online\} 2020 \{cited May, 2020\} Available from: http://www.iamj.in/posts/images/upload/2298_2302.pdf 